\title{
Leadership in Crisis: The Chance for Public Sectors to Turn Challenge into Opportunity
}

\author{
Wang Junjie ${ }^{1}$, Li Yongkang ${ }^{2}$, Bai Yang ${ }^{1}$ \\ 1 School of Public Administration and Policy, Renmin University of China, Beijing, P.R.China, \\ 100872 \\ 2 School of Public Management, Yunnan University of Economics and Finance, Kunming, \\ P.R.China, 650221 \\ (E-mail:wangjunjie268@163.com, LYK@163.com, byking1985@163.com)
}

\begin{abstract}
This study provides a theoretical framework illustrating the predicaments leadership encounters and the deficits leadership exposes in crisis from the perspective of responsibility, public opinion and decision-making. This paper argues that crises brings challenges as well as opportunity for change, therefore with enhanced competence, explicit mission and establishment of strategic plans, the leadership can be remarkably improved in crisis. In conclusion, this paper points out that the key to turn crises into opportunity lies in how to identify and improve the pivotal competence, build a mission shared by all and implement strategies that fit specific environment.
\end{abstract}

Keywords: public crises, leadership, decisionmaking, strategic thinking, competency, mission

\section{Introduction}

Against the social background featuring peace and development, all kinds of hidden crises have been exerting far-reaching impacts on human lives. In accordance with Coombs' (1999) research, these crises, from micro point of view---that is, factors within organizations include personnel, organization atmosphere problems and organization development issues, etc.; from the macro perspective---external factors of the organization, these crises cover problems, such as natural disasters, terrorist attacks and mass disturbances, etc. Parsons (1996) divides crises into three types: (1) abrupt crisis occurs without giving any warnings or bodings, so organizations do not have time to think about and make preparations for them. (2) Emerging crisis, which takes a long time to come into being, can probably be restricted and stopped by organizations. (3) Continuous crisis lasts longer in duration, having a lifecycle of weeks or even years. Emergencies taking place in public areas are called public crises ( $\mathrm{Li}$ Chao-zhi, 2010), the occurrence and outbreak of which will exert serious impacts on the normal operation of society as well as pose great threat and harm on human lives, property and environment that are beyond the normal administrative capacity of the government and society, and therefore special measures have to be taken by the government and society to deal with such crises (Zhang Cheng-fu, 2003). Generally speaking, crises feature emergency (Coral Bell, 1975),uncertainty(Xuelan\&ZhangQiang,2003), variability (Joana;Kim,2011) and abruptness (Herman,1972;Zhang Guo-qing,2003). Compared with ordinary crises, public crises cover a broader range of areas and have longer duration. In terms of the consequences they have, public crises have the distinctive features of violent destructiveness, diffusion and abruptness, which are powerful enough to batter at the weak points of leadership and have relatively far-reaching impacts on leadership (Hermann, 1972; Barton, 2002). This paper argues that for public sectors and leaders, crises do not only signify threats but also opportunities. Having a better understanding of crises conditions and their complexity can help us reduce the impacts crises have on organizations and society. Under the severe test of serious crises, finding the deficit of leadership and constantly making improvement, we can eventually turn the crises into opportunities. 


\section{Leadership Deficits under Crisis Cir- cumstance}

It is not difficult to find leadership deficit in the dilemma of public crisis. Lack of discernment, decision-making failure and improper management of crisis are all reasons that contribute to the leaders' competency problems (Erika \& Lynn, 2005). The different value selections made by leaders under stable and crisis circumstance reveal that the public service value is in a state of deficiency. Even if the leaders have obtained corresponding competency and specific task, however, they still have problem with applying effective solutions to crisis if void of comprehensive strategy plan.

\subsection{Competency Deficiency under Pres- sure}

In Greiner's research (1972), the leaders are confronted with three types of crises due to the development of society and organization: the development of society and organization require better management and therefore lead to a relative insufficiency of leaders' competencies; the crisis generated by arbitrary and the inefficiency and disorder caused by the wrong choice of staff. We can consider the first type of crisis as a test for leadership.

Considering the process of crisis, the crisis latency period requires an insight of crisis, which is a test of the leader's ability to show insight and sensitivity. The insight and sensitivity are the perception of real environment and they provide a way for the leaders to grasp the development direction of public issues. So leaders are able to obtain initiative for next right action through understanding, using and discerning the developing trend of crisis. When crisis breaks out, whether the response from public sectors is in time is a test of leaders' mentality, ability to make decisions and summon up other groups. Leaders with stable mentality are good at grasping pivotal opportunity and making judgment within the shortest time. And then based on the correct decision, leaders can summon organizations to fight with the crisis through attracting and influencing the subordinate of their own. When crisis spreads, the need of controlling crisis is a test of the leader's ability of control and coordination. The ability to control refers to the ability that reduces major issues to minor ones and prevents the negative situation from going out of control or extending; the ability to coordinate refers to the ability that uses resource flexibly and that ensures the efficiency of control. When the crisis is dispelled, it is a test of the leader's abilities of learning and innovation. Leaders needs to learn useful experience from the crisis issue first, and then seek new solutions to solve the problems by means of innovating methods, technique and theory out of the frame of the current situation (Li Chao-zhi, 2010). We should also notice that the leadership deficit under crisis situation is not all due to personal reasons because the complexity of crisis. The restriction of playing a leadership role under current Institutional and social environment should also be thought over.

\subsection{Mission Deficiency in Emergency De- cision}

Normally, we hope leaders behave as the public expect them to do all the time, especially when benefit is involved. In the management of crisis, however, we recognize that although leaders with different views of management all have the ability to dispel crisis, the influences of their management strongly distinguish from each other. Some leaders obtain more trust while others may be expelled from the area of power. This is attributed to the ambiguity of the mission of leaders. There is sufficient time for leaders to ponder on public issues in a stable environment, so their decisions may include higher level of the goals, namely, the mission, whether they are on purpose or not. Under crisis situation, however, the only objective leaders tend to consider is how to eliminate the current crisis and as a result, this objective deviates from the value request of the public_- providing public services. Therefore, explicit mission for the leaders and organizations as well as the guidance of ethic, such as ethic of fair and ethic of care are needed in making rational decisions in crisis. Ethic of care brings more efficient effect in the crisis management, since it put the need of human survival and society development at the first place, which is the most important value of the leaders' mission management in public sectors. In private sectors, organizations' missions vary from one to another, though the pursuing of profit is always the theme. The public sectors are more complex than companies, although their jobs mainly focus on one issue--providing public service. Normally, strong performance was most often associated with those institutions that sought to align organizational processes and arrangements with their mission 
statement (Bart \& Tabone, 1998). It's risky if the crisis management is short of mission. One can imagine the spread of disasters caused by crisis when an organization lacks performance in the management of crisis, which will deeply harm the society. Nowadays many researches are focusing on the government administration innovation, and we should notice that to innovate in government against these crises, build confidence and trust in the public and encourage collective approaches requires more than just management and governance - it requires leadership at all levels in setting a vision and turning that vision into publicly valuable reality (O’Neill, 2002).

\subsection{Strategy Thinking Deficiency under Abrupt Crisis Situation}

Generally speaking, organizations survive in crisis gain the ability of handling next crisis better. We typically attribute this result to the reason that organizations have settled the crisis more positively (Lerbinger, 1986). It is much better to take action fast and make mistakes occasionally than act too slow (Katsuhiko \& Michael, 2004). The advantage of strategy lies in it can make sure organizations take fast actions and thus see to it that the crisis situation would be under well control.

As the environment is always obscure, the efficiency of leadership should depend on various resource, intuitions and rational thinking to assure accurate explanation. Intuition and rational analysis are viewed as two equally important recognition systems of the high quality strategic decision (Eugene \& Erella, 2004). But the recognition system of the high quality strategic decision has been broken under crisis circumstance: the characteristic of crisis influences the correct intuitive judgment, for the uncertainty of crisis often leads to failure of the plan, which tends to damage the expected results of the judgment. Therefore, the reality of crisis is always the negation of intuitive judgment. On the other hand, the objective reality made by crisis breaks the environment which rational analysis depends on, leading to the lack or inefficiency of leader's rationality. Compared with the above consequences, the leaders' loss of enthusiasm to crisis is even worse, which results in the current situationleaders don't value the strategy of crisis management because they consider it is overvalued. This can be proved by the strategy imbalance under crisis. It is easy to tell crisis situation of- ten put the leaders in a conflict situation, which is difficult for anyone to conquer. However, for those leaders who approve for the strategy, the correct thinking is to answer what happens and how it happens, as well as what actions to be taken to guarantee it won't happen again (Coombs, 2004).

\section{Public Crises: Bearers of Opportunities?}

Crises themselves are neither good nor bad in nature. They are just considered to be harmful in many cases. If organizations can come up with effective measures to manage crises prevention, then the damage caused by crises can be greatly reduced. However, if organizations just simply respond to the crises, the potential opportunities will be covered up by the damage (Penrose, 2000). In light of a series of researches, despite of the destructive results, the crises have also brought a lot of opportunities to change the world.

In terms of organizations, first, crisis provides organizations with an opportunity to enhance their reputations by effectively managing the crisis (Fink, 1986). Second, crisis provides organizations with a number of internal opportunities. For example, crises enable organizations to deal with organizational problems and focus organizational energies on new directions (Kerchner, 1982); unfreeze old behaviors and renew growth processes (Fink et al.,1971); generate innovations for managing the crisis; clarify relevant values(Hermann,1963) and change shared interpretive schemes(Bartunek,1984).

As far as leaders are concerned, the emergence of crises is an important opportunity for them to show their charisma, in other words, crises to a certain extent shape the leaders' charisma, which means compared with their counterparts in normal situations, leaders in crisis are often considered as more competent (Pillai,1996). The leadership charisma can be explained from the perspective of social contagion---there is such a group of people who tend to release their suppressed or potential behaviors when they see other people in public places. A lot of people possess a kind of suppressed social trait called heroism which will be activated when they meet the right leaders and careers, and this kind of activation is most likely to take place when one's dignity and survival are threatened(Yukl, 2002). So in a state of crisis, people always hope that a strong 
and competent leader can help them find the way out or that a leader with charisma will stand out so that they can at least anchor their hopes on him. The tenacity, calmness, clarity of mind that leaders demonstrate are all that normal people want of and are the exact abilities that leaders need to cope with crises. That is why the intelligence that leaders display in their behaviors are well applauded and highly praised---tiny charm has been magnified and the charisma of leaders has been enhanced. The charisma leaders display in crises are much stronger and can be more easily been perceived (Halverson et al.,2004). In a word, opportunities reside in any crisis, a crisis may generate a new leader or accelerate the transformation of working process, which may prove to be beneficial in the long run(Burnett, 1998).

\section{The Choice of Approaches to Turning Crises into Opportunities}

The enhancement of people's initiative and exposure of some objective problems provide resource advantages for the resolving of crises and feasible fundamental conditions for the transformation of crises. Some experts hold that leaders have to act in accordance with three key principles in crisis situations, which are: (1) actively taking part in crisis management and bringing the leadership into full play, (2) setting the overall interests above everything else and conveying visions to the public,(3)Working with crisis management teams (Sherman, 2011). During crisis settlement, these three principles are based on one premise that the leader should possess corresponding competence, a strong sense of mission and thinking that turns from target management to strategic management.

\subsection{Enhancing leaders' competencies}

The building of leadership competencies in crisis is a systematic process which involves capability to recognize early warnings and to make decisions rapidly, rapid response to resources allocation and information communication as well as the ability of post-crisis learning and reflection. It also requires the basic ability of collecting, analyzing and grasping of all sorts of information and excellent psychological quality (Zhu Rui-bo, 2009). Considering the factors that have greater impact on leaders in crises and how to facilitate the miti- gation of crises, leaders should put emphasis on the following aspects:

Leaders' sensitivity to crises and their capability of recognizing crises have to be improved, and their execution to be enhanced. In the course of preparing for the prevention of crises, although comprehensive and wellplanned precautionary measures can be taken, it is still impossible to prevent crises from happening. The real challenge is about responding to crises timely and implementing supporting strategies immediately so as to reduce the damage of crises (Darling, Hannu\& Raimo, 1996). Generally speaking, the 24 hours after crises take place are critical. If an "information vacuum" that has not been filled exists in an organization, then some other people will fill the vacancy. The longer the delay is, the greater the possibility that the false being regarded as truth (Coombs, 2004). Therefore, it is necessary to foster leaders' acute observation so that they can recognize the sign of crises and come up with counter-measures as early as possible. To enhance leaders' executive ability is not to encourage leaders to act boldly but to pay attention to whether the strategies are compatible because only on the basis of compatibility can the strategies be executed.

Leaders need to improve their ability of internal communication, enhance the cohesiveness within organizations and promote communication with external groups so as to increase their public confidence. Internal communication ability can be improved through acquirement of communication skills as well as through cultural construction to build a harmonious environment for communication. By adjusting target and communication, the cohesiveness within the organizations can be achieved. Communication with external groups depends on the following principles: being fully prepared for crises, taking rapid and honest actions and complete exposure of crises. External communication can be carried out in light of the three " $A$ " perspectives, namely, "acknowledging "actuality, making specific "actions" to deal with or minimize damage and telling the public what to do to "avoid" failing into the same trap again. The purposes of both internal and external communication are to clear misunderstanding and strengthen cohesiveness and mutual trust. From the standpoint of the public, their belief is in the Social system rather than an individual (Giddens, 1990; Luhmann, 1988). Therefore, to build a lasting 
trust mechanism requires a good system based on a mutual trusting culture.

\subsection{Strengthening mission management}

The reason why mission is so important lies in it expresses the meaning of "Why to do". If an organization has no mission, then it may only know "what to do" and "how to do" while having no idea of "why to do". Studies have shown that the management of mission statement will affect its implementation; and the contents of mission statement and its construction process may significantly improve the level of performance (Jatinder, 2003).

Mission is the guiding principle that answers why the organization exists and how to develop the organization, it explains the organization's core values. To achieve goals and create public value, Moore (1995) holds that leaders of public sectors must answer three questions: (1)whether the objectives of the organization is valuable,(2)Whether the objectives can get the support from the political and legal fields , (3) in light of the management and operation of the organization, whether this goal can be achieved. Accordingly, the leaders should first identify the value of work, actively seek external support to improve the organizational capability and finally achieve the goals. The public sector is different from the private one, although mission plays a role of guidance and motivation for all organizations' leaders, leaders of public sector are involved in a higher level of commitment and more contributions to help organizations fulfill the service functions, therefore it is of more far-reaching meaning for them to establish a mission. In a state of crisis, the mission is the cornerstone that inspires all the members to work hard and guide them to act without neglecting the public interests.

The ultimate sustenance of mission management relies on individuals, while the mission of public sectors on civil servants. The basic ways to manage the mission of civil servants lie in creating a culture of mission among the civil servants, using vision and objectives to guide and regulate their management and practice, incorporating the fulfillment of mission into their performance assessment, including the mission of civil servants into their job responsibilities and regulating the behavior of civil servants (Chen Hui, 2007).

\subsection{Transforming the pattern of strategic thinking}

Strategic thinking and specific decisionmaking prior to crisis can ensure the effectiveness of crisis management, however, hasty decisions made in the midst of a crisis often lead to a situation in which leaders and organizations are managed by crisis (Richardson, 1992; the Pitman \& Scholes, 1993). In order to grasp the initiative of crisis management, leaders should change the pattern of strategic thinking and develop a strategic plan to deal with the crisis. In chronological order, Strategic planning and management usually consist of four steps---strategic analysis, strategic options, strategy execution and control, strategic assessment and feedback (Richardson, 1992; Johnson \& Scholes, 1993), which have a clear relevance with the life cycle of crisis that include Pre-crisis, crisis outbreak, crisis spreading and post-crisis:(1) Pre-crisis period is a critical time to make strategic planning and development. (2)In the period of crisis outbreak, right strategy should be chosen to deal with specific crises. (3)In the stage of crisis spreading, the implementation and control of strategies can effectively reduce the severity of crisis.(4)In the post-crisis period, it is important to assess and get feedback of the effect of strategies, to formulate and adjust the strategic plan so as to address future challenges. It can be seen from the crisis cycle and the process of strategy implementation that gaining opportunity cannot depend on fortune and resources but on the quality and speed of decisions and actions taken by leaders during this period, and strategic management should not be a passive action but a proactive and positive one, thus strategic thinking and strategic actions will be more effective.

Paying attention to the long-term development does not mean the details can be ignored, and any performance conducive to achieving goals deserves attention. This is especially true in crisis settlement, just as subtle factors can induce crisis, tiny performance is probably the key to settle the crisis. High performing crisis management ultimately depends on crisis management plans and people. A set of highperforming crisis management strategy generally consists of explicit leadership, teams, tasks and clear division of labor, continuous improvement and providing support through training and regular meetings; coordination and regulation between the different levels and departments (Stanley \& Niveen,2003). The value of the strategy is also embodied in the compre- 
hensive analysis of affaires, which is similar to total quality management, the implementation of which in crisis shows the organizations' adherence to their responsibility for their clients and commitment to their mission.

\section{Conclusion}

For any organization and leader, crises and opportunity are just like two sides of a coin. Currently leadership building of public sectors aims at solving problems rather than the realization of public values, this short-sightedness imposes restrictions on the possibility for crises to transform into challenges, so this paper argues that it is insufficient to discuss competency building just in context of crises, and while

\section{References}

[1] Bart, C.K., \&Tabone J.C.Mission statement rationales and organizational alignment in the not-for-profit health care sector. Health Care Management Rview.1998, 23(4), pp.54-69.

[2] Burnett, J. J. A Strategic Approach to managing crises. Public Relations Review. 1998 (24), pp. 475

[3] Bartunek, J. M. Changing Interpretive schemes and organizational restructuring: The example of a religious order, Administrative Science Quarterly 1984(29), pp.355-372

[4] Coombs,W.T. Impact of past crises on current crisis communication: Insights from situational crisis communication theory. Journal of business Communication, 41 2004(7), pp.265-289

[5] Coombs, W.T. Ongoing crisis communication: Planning, managing and responding. Thousand Oakes, CA: Sage, 1999

[6] Erika Hayes James\&Lynn Perry Wooten. Leadership as (Un)usual:How to display competence in times of crisis.Organizational Dynamics, 2005 ,Vol. 34, No. 2, pp.141-152

[7] Eugene Sadler Smith\&Erella Shefy.The intuitive executive: Understanding and applying 'gut feel' in decision-making, 2004, pp.76-91

[8] Fink, S. L. Crisis management: Planning for the inevitable. Amacom, New York, NY, 1986. realizing the values of public sectors, they should at the same time advocate the responsibility of government and make strategic initiatives. Only core-interest centered strategic deployment that orientates towards long-term benefit can make public sectors see the opportunity hidden behind crises and grasp the opportunity for reform. However, it is still an uncertainty whether the value judgments of leaders earnestly adhere to their mission and strategy when they are confronted with challenges of public crises. To choose leaders and foster their sense of mission in light of their motivations of public service is a likely breakthrough point to reduce uncertainty.

[9] Fink, S. L., Beak, J., \& Taddeo, K. Organizational crisis and change, Journal of Applied Behavioral Science 1971(7),pp.15-37

[10] Greiner, L. E. Evolution and revolution as organizations grow, Harvard Business Review, Reprint Service, 1972, pp.37-46

[11] Hermann, C. F.International Crisis: Insights from behavioral research. New York: Free Press, 1972

[12] Kerchner, C. T. \& Schuster, J. H. The uses of crisis: Taking the tide at the flood, The Review of Higher Education Spring, 1982 5(3), pp.121-141

[13] Katsuhiko Shimizu \& Michael,A.Hitt. Strategic flexibility: Organizational preparedness to reverse ineffective strategic decisions, Academy of Management Executive.2004, pp.44-59

[14] Luhmann,N.Familiarity.Confidence, trust: Problems and alternatives. Oxford: WileyBlackwell, 1988, pp. 94-107.

[15] Laurence Barton. Crisis in organizations. Tsinghua University Press, 2002

[16] Li Chao-zhi. Leadership in the state of public crisis. Leader Science.2010 (7), pp.34-35 (In Chinese)

[17] O'Neill O .A question of trust: The BBC Reith Lectures 2002. Cambridge: Cambridge University Press.2002

[18] Lerbinger, Otto. Managing corporate crises: Strategies for executives. Boston: Barrington Press, 1986, pp. 88 -90.

[19] Parsons, W. Crisis management. Career Development International, 1996 Vol. 1, Issue: 5, pp.26-28.

[20] Penrose, J.M. The role of perception in crisis planning . Public Relations Review2000, 26(2):155-171 
[21] Pillai R. Crisis and the emergence of charismatic leadership in groups: An experimental investigation .Journal Of Applied Social Psychology. 1996(3), volume: 26, issue: 6 pp.543-562

[22] Richardson, B., \& Richardson, R. Business planning: An approach to strategic management (2nd Ed.). London: Pitman, 1992

[23] Sherman, R.How to communicate during times of crisis. Business credit 103 (10) November/December 2011, pp.30-31

[24] Stanley J. Smits\& Niveen Ezzat Ally. Thinking the unthinkable - Leadership's role In creating behavioral readiness for crisis management. Competitiveness Review: An International Business Journal incorporating Journal of Global Competitiveness, Vol. 13 Issue: 1, pp.1 - 23

[25] Yukl, G. Leadership in Organizations (5th Ed.).Upper Saddle River, NJ Prentice Hall.2002

[26] Zhu Rui-bo. Crisis life cycle and the enhancement of crisis leadership [J].Leadership Science, 2009(6-mid), pp26-28 (In Chinese) 